\title{
Re-design of a MOOC RLMS based in Moodle
}

\author{
Felix Garcia-Loro, IEEE Student Member ${ }^{1}$, Pablo Losada1, Elio Sancristoba ${ }^{1}$, IEEE Member ${ }^{1}$, Gabriel Diaz, IEEE \\ Senior Member ${ }^{1}$, and Manuel Castro, IEEE Fellow ${ }^{1}$ \\ ${ }^{1}$ UNED, Spain, fgarcialoro@ieec.uned.es, plosada@ieec.uned.es, elio@ieec.uned.es, gdiaz@ieec.uned.es, \\ mcastro@ieec.uned.es
}

\begin{abstract}
In 2013, Electrical and Computer Engineering Department (DIEEC) of the Spanish University for Distance Education (UNED) launched the first Massive Open Online Course (MOOC) that, besides the usual features of these courses, includes the extensive use of a real remote laboratory dedicated to practices in electronic circuits. The MOOC was named: "Circuits Fundamentals and Applied Electronics" (BCEP; in Spanish "Bases de Circuitos y Electrónica Práctica") and has been re-edited every year since then. Although the nature of this MOOC is completely open, this course targets especially people with at least basic circuits knowledge. The main objective of the course is to acquire practical competences in basic electronic circuits and provide to students a work philosophy when facing up real expeThrimene tcoreation. of the MOOC is the remote laboratory VISIR, which has been given the leading role in the course: evaluation and activities spin around the remote laboratory and the objectives and evaluation are focused on handling the instruments and the interpretation of the measurements obtained from the remote laboratory, knowledge on electronics are on no account evaluated despite being necessary to understand the behavior. This paper describes the design, development and first results and impressions of a novel Massive Open Online Courses (MOOC) on industrial electronics practices. This was possible by implementing a state-ofthe-art remote laboratory within the MOOC to allow online delivery of such practices-which makes this MOOC a first of its kind. Thus, the core of the MOOC is the remote laboratory Virtual Instrument Systems in Reality (VISIR) and the experimentation carried out on it. This paper presents the framework and structure of a new family of MOOCs and remote lab VISIR integration obtaining Remote Learning Management System (RLMS) evolved from BCEP MOOC. The structure make the most of BCEP MOOC learning analytics and the logs stored by VISIR. The students' profile interested in this kind of MOOCs and their needs for getting advantage out of the remote laboratory have been also considered..

Keywords-MOOC; RLMS; Remote Laboratory; VISIR; electronics competences.
\end{abstract}

Digital Object Identifier

(DOI):http://dx.doi.org/10.18687/LACCEI2016.1.1.146

ISBN: 978-0-9822896-9-3

ISSN: $2414-6390$

$14^{\text {th }}$ LACCEI International Multi-Conference for Engineering, Education, and Technology: "Engineering Innovations for Global Sustainability", 20-22 July 2016, San José, Costa Rica. 


\title{
Re-design of a MOOC RLMS based in Moodle
}

\author{
Felix Garcia-Loro, IEEE Student Member ${ }^{1}$, Pablo Losada ${ }^{1}$, Elio Sancristobal, IEEE Member ${ }^{1}$, Gabriel Diaz, IEEE
}

\author{
Senior Member ${ }^{1}$, and Manuel Castro, IEEE Fellow ${ }^{1}$ \\ ${ }^{1}$ UNED, Spain,fgarcialoro@ieec.uned.es, plosada@ieec.uned.es, elio@ieec.uned.es, gdiaz@ieec.uned.es, mcastro@ieec.uned.es
}

\begin{abstract}
In 2013, Electrical and Computer Engineering Department (DIEEC) of the Spanish University for Distance Education (UNED) launched the first Massive Open Online Course (MOOC) that, besides the usual features of these courses, includes the extensive use of a real remote laboratory dedicated to practices in electronic circuits. The MOOC was named: "Circuits Fundamentals and Applied Electronics" (BCEP; in Spanish "Bases de Circuitos y Electrónica Práctica") and has been reedited every year since then. Although the nature of this MOOC is completely open, this course targets especially people with at least basic circuits knowledge. The main objective of the course is to acquire practical competences in basic electronic circuits and provide to students a work philosophy when facing up real experithrenomiof. the MOOC is the remote laboratory VISIR, which has been given the leading role in the course: evaluation and activities spin around the remote laboratory and the objectives and evaluation are focused on handling the instruments and the interpretation of the measurements obtained from the remote laboratory, knowledge on electronics are on no account evaluated despite being necessary to understand the behavior. This paper describes the design, development and first results and impressions of a novel Massive Open Online Courses (MOOC) on industrial electronics practices. This was possible by implementing a state-ofthe-art remote laboratory within the MOOC to allow online delivery of such practices-which makes this MOOC a first of its kind. Thus, the core of the MOOC is the remote laboratory Virtual Instrument Systems in Reality (VISIR) and the experimentation carried out on it.
\end{abstract}

This paper presents the framework and structure of a new family of MOOCs and remote lab VISIR integration obtaining Remote Learning Management System (RLMS) evolved from ВCEP MOOC. The structure make the most of BCEP MOOC learning analytics and the logs stored by VISIR. The students' profile interested in this kind of MOOCs and their needs for getting advantage out of the remote laboratory have been also considered.

Keywords-MOOC; RLMS; Remote Laboratory; VISIR; electronics competences.

\section{INTRODUCTION}

Universities and educational organizations or institutions, when designing any electronics course, trust in experimentation through laboratory practices in order to build successful cross-curricular capabilities and capacities. In electronics courses there is a need to have practical experiences, the benefits of electronics laboratory practices are widely known for professionals and necessary for any person who seeks for a broad comprehension of the real-time performance beyond the ideal modelling. Therefore, when designing any electronics course, the laboratory practices are one of the pillars on which the learning is established.

Broadly speaking, the experience acquired through laboratories provides active learning complements to traditional lecture-based education and an understanding of the subject beyond ideal modelling. In-person laboratories, remote laboratories, virtual laboratories and simulators are the options available for educational institutions in order to complement the learning materials and are necessary for the structure of courses in which experimentation plays an essential role [1]-[5]. A review of the current literature shows a great number of universities or organizations that have created their own virtual and remote laboratories to support life-long learning and students' autonomous learning activities [6]-[10].

Remote laboratories, if properly designed and managed, provide controlled and safe scenarios at the expense of flexibility. This loss of flexibility when experimenting is due to the protections and constraints established by teachers in the design stage of the experiments and limitations established by remote lab operation. For example, destructive experiments that students may be carried out erroneously in in-person laboratories, cannot be allowed in remote labs. But sometimes, this loss of flexibility in the interest of safety also limits the students' freedom, thus limiting students' options to explore.

VISIR is a remote lab for electric and electronic circuits experiments, developed at Blekinge Institute of Technology (BTH) in Sweden and in use in several universities all around the world [10]. In VISIR, the traditional equipment (DCpower source, function generator, multimeter and oscilloscope) are replaced with an equipment platform, which is suited for remote control such as PXI (PCI eXtensions for Instrumentation), LXI (LAN eXtensions for Instrumentation) and GPIB (General Purpose Interface Bus) [1]. Therefore, VISIR is a real laboratory as in-person laboratories are, but designed for remote access. Its integration in LMS (Learning Management System) evolves into a Remote-LMS (RLMS); a responsive design of the whole system evolves into a responsive-RLMS (r-RLMS).

The essential difference between remote laboratories and in-person laboratories results from how the interaction between student and workbench is performed. Therefore, remote laboratories have very limited ability to provide manual skills; "Physical presence however is only one element in the perception of reality, a student's subjective mental reality" [3], [12], [13]. This difficulty can be overcome by immersing users in the laboratory by means of its interface.

The possibility of a direct comparison between the different alternatives is constrained by a lack of uniform criteria with which to evaluate the effectiveness of laboratory [2], [14], [15]. It is impossible to conclude that any type of laboratory is superior to another objectively, but also each one provides different learning outcomes [2], [15]. Regardless, the most effective solution with regard to meeting the expected learning outcomes is still a combination of the methods [2].

Digital Object Identifier (DOI): http://dx.doi.org/10.18687/LACCEI2016.1.1.146 ISBN: 978-0-9822896-9-3

ISSN: 2414-6390

$14^{\text {th }}$ LACCEI International Multi-Conference for Engineering, Education, and Technology: “Engineering Innovations for Global Sustainability”, 20-22 July 2016, San José, Costa Rica. 
Distance education has become widespread in the last decade and has fostered lifelong learning and continuing education patterns, allowing access to learning resources at anytime and from anywhere. It has been possible thanks to the internet development and technologies associated with learning tools for a new teaching pedagogy. To support lifelong learning and students' autonomous learning activities, remote experimentation has become a challenge in electronics courses. The way the universities and educational organizations or institutions deliver remote experimentation to students in distance learning environments has become a challenge.

Nowadays, there is an extensive variety for providing theoretical contents in distance learning (videos, documents, tutorials, scaffolding activities, peer-to-peer reviews, forums, etc.) to students. These tools, by an efficiently and appropriate selection from professors and use from students, can complement or replace successfully in-person education, even they can reach some aspects that in-person education cannot achieve. Unfortunately, practical issues are not as developed as theoretical ones are. A first approach to this problem is clearly the use of simulators and virtual labs. Although, they are still a bit far from providing to student the real performance and features of equipment under real-life operation conditions. The major challenge is the provision of laboratory working online along with the theoretical contents in a massive context.

\section{MOOC PLATFORM}

\section{A. UNED-COMA Platform}

UNED-COMA platform (Massive Open Online Course in Spanish: Curso Online Masivo Abierto), aimed at the deployment of MOOCs from different departments of UNED, is an UNED-Abierta (Open-UNED) initiative and part of its platform [23]. Open-UNED was created by the UNED in order to draw together Open Educational Resources (OER) from UNED. The platform explodes the rich experience of UNED educational system in distance education.

UNED-COMA platform is not intended/designed for the integration of a remote laboratory in MOOCs. Therefore, due to the technical problems resulting from the adaptation, is not possible to cross the data available in the UNED-COMA platform and the one registered in VISIR. Consequently, it is not possible to carry out a reliable learning analytics. Furthermore, UNED-COMA platform does not provide any type of tool for teachers to track the progress of students in the MOOC, only provides general information (number of enrollments, number of badges obtained, etc.).

In order to obtain more specific information, i.e. for an individual monitoring or to obtain the grades of the students, the databases (PostgreSQL, MongoDB) of the MOOC platform have to be analyzed. Unfortunately, UNED-COMA no longer provides access to the databases. In this regard, a MOOC platform with the necessary tools for a deeper analysis of the students' learning process and that integrates both environments (MOOC and remote laboratory) seems necessary in order to evaluate the convenience of the supplementary documentation (videos, documents, activities, etc.) and their relationship with learning and dropout.

Besides, the possibilities offered by UNED-COMA platform, when establishing activities and assessment tasks in the designing phase of the course, are very limited: the viewing of videos, video-questions or $\mathrm{P} 2 \mathrm{P}$ activities are the assessment tools for evaluating student progress. Assessment tools provided by the platform are not ductile for any type of subject, but even less when the target is to evaluate the practical skills acquired.

\section{B. Moodle as a MOOC Platform}

Moodle (the Modular Object Oriented Dynamic Learning Environment) development is increasingly influenced by Moodle community of developers and users [17]. The platform offers more than MOOC-platform edX in terms of educational tools, analytics and SCORM compliance[18]. Moodle offers a full-featured flexibility for the provision of instructional materials and assessment tools; it is completely customizable LMS (Learning Management System). Another advantage of Moodle with respect other platforms is that it is provided freely as Open Source software under the GNU General Public License (GNU GPL or GPL).

The trade-off in Moodle is that the number of configuration options can be daunting, and system performance suffers with larger numbers of students [18].

\section{COURSE STRUCTURE}

\section{BCEP MOOC in UNED-COMA platform}

With respect to the objectives associated to the principles established when designing the course, the structure of the MOOC could be divided into 3 blocks:

- Block 1: The purpose of the activities associated to this block is the gathering of information: basic data such as age, genre, country, labor situation, etc.; training information such as the maximum academic level, previous experience in any kind of laboratories, training, level of knowledge to address the learning outcomes effectively, etc.; and finally the motivation of the enrollment in this course such as the expectations about the remote laboratory, the interest of the students in electronics, etc. The method employed for obtain this information are the non-evaluative exams (two non-evaluative mandatory exams throughout the course) and surveys (three optional surveys during the course). This block is made up of Module 0 and Final Module.

- Block 2: The main idea behind this module is to give the students a work philosophy on how to deal with laboratory practices. Another objective of this block is to disenchant and/or to cause the "MOOCaholics"

$14^{\text {th }}$ LACCEI International Multi-Conference for Engineering, Education, and Technology: “Engineering Innovations for Global Sustainability”, 20-22 July 2016, San José, Costa Rica. 
dropout. The reason for this goal is caused by VISIR restrictions and to limit, to the extent possible, the access to the remote lab to those students who cover the training specified in the syllabus. Block 2 is made up of Module 0 and Final Module.

- Block 3: This block is where the students interact with the remote laboratory VISIR and where the designed practices take place. This block is made up of Module 3 to Module 8.

In first modules, the MOOC aims to provide students with a work philosophy to follow in the subsequent modules. This work philosophy proposes the students these sequential steps:

1) Theoretical analysis of the circuit.

2) Performing an analysis of the circuit using a simulation tool with the purpose of monitoring the timedependent signals.

3) Experimenting in a real environment (laboratory).

4) Analyzing the behavior and comparing the limitations, advantages, differences, etc. between the different methods.

Unfortunately, the platform allows access to any module without any restriction. The original design limited the access to a module to those students who have completed the previous ones. This issue was addressed when designing the course with those responsible for the implementation and development of the platform in the UNED; it was considered a feature to add, but secondary.

The course structure comprises 8 modules: Module 1 is dedicated to electronics simulation: MicroCap software is proposed and several demonstratives videos and a manual are supplied to students together with documentation about the theoretical contents of the course; In Module 2 the remote laboratory VISIR is introduced to students, but they do not have granted access yet, demonstrative videos with the special features of every instrument and a manual are provided to students in order to familiarize with the laboratory workbench; From Module 3 to Module 8 students interact with lab, building real circuits with VISIR and taking measurements related with them. Every module is focused in one or more functionalities and handling of the laboratory instruments (breadboard, multimeter, function generator, power supply and oscilloscope). Module 3 and Module 4 aim specially in teaching the handling of the lab equipment, components and instruments, whereas Module 5 to Module 8 are centered on showing the behavior of real components and specific features

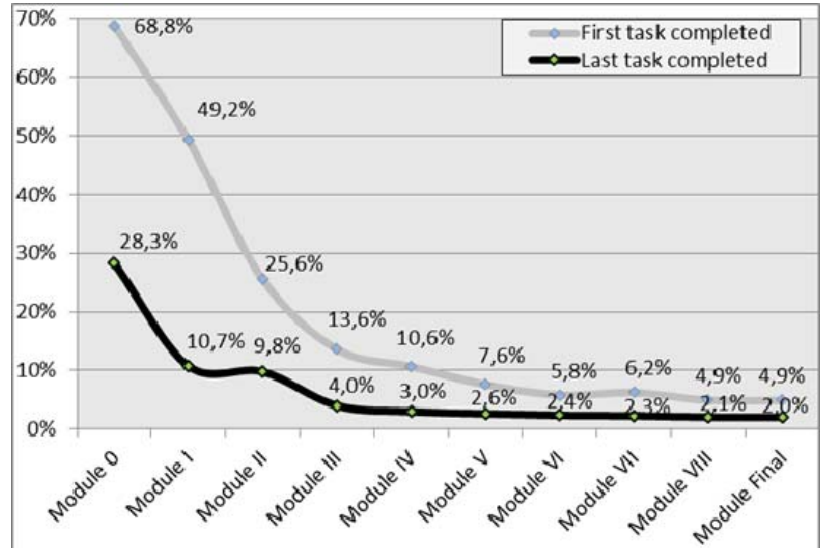

of the instruments (coupling, trigger, cursors, measurements menu, etc.).

Figure 1: Dropout. Percentage expressed from enrollments

The course contains 97 evaluative activities, 55 standard multiple choice questions (including single-answer questions and multiple-answer questions) and 42 videos. The weight of the videos is $30 \%$ of the final grade and they need 80 over 100 to obtain the certifying badge. Besides this structure, two extra modules (one before the beginning of the course and another one once the students have completed the course) are responsible of compiling the students' profile and their knowledge level by means of optional surveys and questions about basic circuit analysis and electronics components. UNED-COMA platform doesn't have any tool to carry out surveys, so an external tool has been used to accomplish it, therefore there is no way to identify the behavior of students according to their profile.

\section{Course Data and Students Feedback}

The dropout rate has been high as is usually in this type of courses (Figure 1); less than $4 \%$ have obtained the course credential badge of those who started the course. One of the main reasons for this dropout have been the need of a theoretical background to understand circuits' behavior. This fact is reflected in the high dropout rate in the first modules.

A bad design of the MOOC activities (both laboratory experiments and associated activities derived from the measurements from VISIR remote lab) may cause to students to focus more on completing them than in analyzing the results and understanding the behavior of the circuit and/or

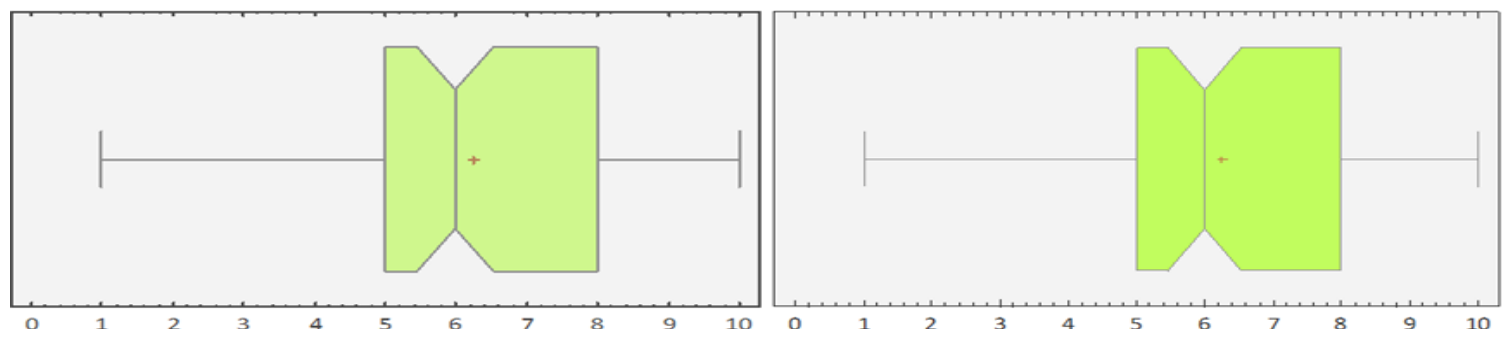

Figure 2: Box plots for: (left) “The realization of the experiments have been:”; (right) “The activities associated to the experiments have been:”. Answers from ' 1 ' (very shorts) to '10' (very long). Answers from students who has completed at least some activities in BCEP MOOC.

$14^{\text {th }}$ LACCEI International Multi-Conference for Engineering, Education, and Technology: "Engineering Innovations for Global Sustainability”, 20-22 July 2016, San José, Costa Rica. 
components. In this regard, when students have been asked about the duration of the experiments (Figure 2, left) and activities associated (Figure 2, right) with the experiments in general they agree that, both activities, they have had to perform in the remote laboratory (measurements, wirings, variations of the same circuit, etc.) and the activities derived from it (calculations, graphs, tables, etc.), are long. Figure 2 shows that both distributions are slightly skewed to the right (the mean is slightly greater than the median), exceptional high values impact the mean and pull it to the right, but both distributions are concentrated between " 5 " and " 8 " (lower and upper quartiles from Figure 2 and TABLE 1). So, in general, the students' opinion opts to consider that the course's activities are long or very long. Figure 2 and TABLE 1 take into account all students who have completed several activities into the BECP MOOC, the trends shown in both are more pronounced when taking into account only those students who have completed the course (their opinion have more judgment elements), as reveal Figure 4.

TABLE 1

STUDENTS’ OPINION ABOUT ACTIVITIES.

\begin{tabular}{|r|c|c|}
\cline { 2 - 3 } \multicolumn{1}{c|}{} & $\begin{array}{c}\text { Activities in } \\
\text { VISIR }\end{array}$ & $\begin{array}{c}\text { Activities } \\
\text { derived }\end{array}$ \\
\hline very short - 1 & $7,26 \%$ & $5,03 \%$ \\
\hline $\mathbf{2}$ & $1,68 \%$ & $1,68 \%$ \\
\hline $\mathbf{3}$ & $2,79 \%$ & $4,47 \%$ \\
\hline $\mathbf{4}$ & $5,03 \%$ & $5,03 \%$ \\
\hline $\mathbf{5}$ & $23,46 \%$ & $24,02 \%$ \\
\hline $\mathbf{6}$ & $13,97 \%$ & $12,29 \%$ \\
\hline $\mathbf{7}$ & $15,08 \%$ & $15,08 \%$ \\
\hline $\mathbf{8}$ & $14,53 \%$ & $15,64 \%$ \\
\hline $\mathbf{9}$ & $6,70 \%$ & $6,15 \%$ \\
\hline very long - 10 & $9,50 \%$ & $8,94 \%$ \\
\hline
\end{tabular}

Once the course was closed, the students are asked to answer a survey. But, although only $9.1 \%$ of students who

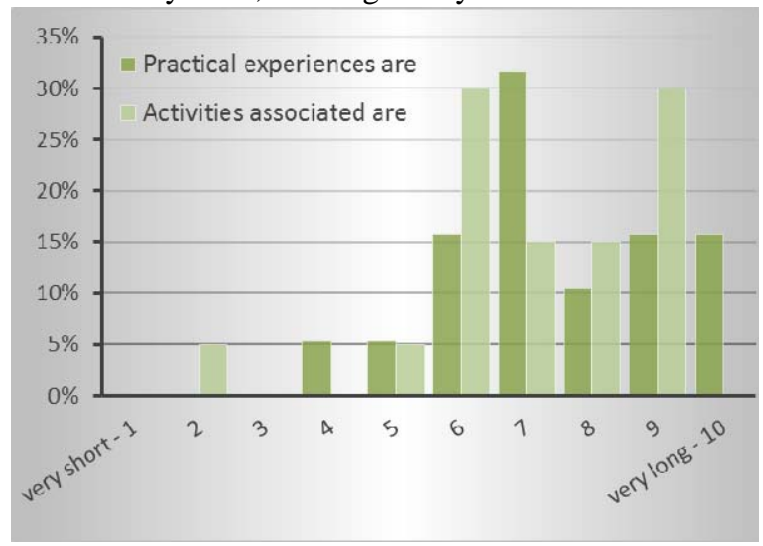

Figure 4: Answers from students who has combleted BCEP MOOC.

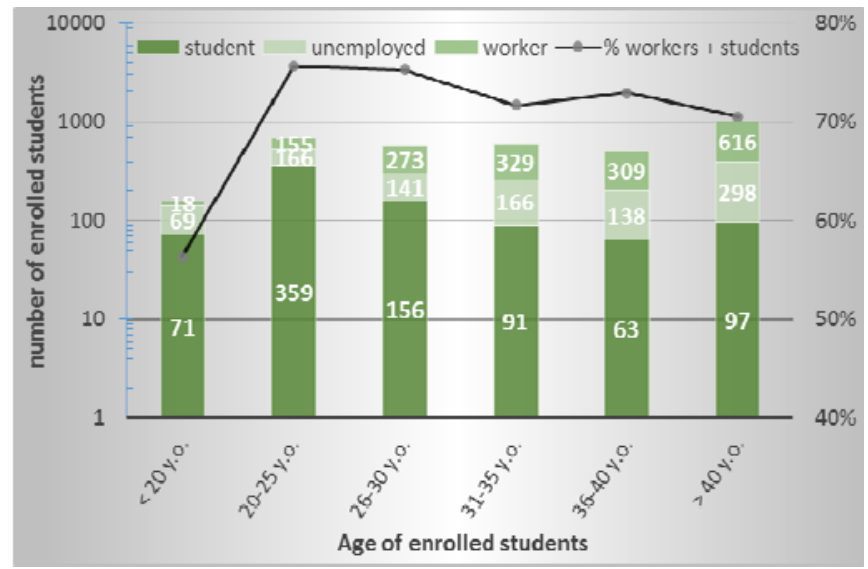

Figure 3: Main y-axis: Enrolled students grouped by age and divided by previous experience in any kind of laboratory (related to electronics or not); Secondary y-axis: percentage of each group to the total and percentage of students with previous laboratory experience of each group

answered the survey had completed the course, the survey shows that participants were interested in new courses related to electronics and practical experiences (TABLE 2). Moreover, only $1.78 \%$ of those students who did not complete the MOOC alleged that the contents/thematic did not become of their interest.

TABLE 2

StUdENTS’ OpINION ABOUt New COURSES OR EDITIONS.

\begin{tabular}{|l|c|c|}
\hline \multicolumn{1}{|c|}{ Statement } & agree & $\%$ \\
\hline I would be interested in a re-edition of this MOOC & 166 & $65,60 \%$ \\
\hline $\begin{array}{l}\text { I would be interested in a similar practice-based } \\
\text { MOOC on electronics but more basic than this } \\
\text { MOOC }\end{array}$ & 97 & $38,30 \%$ \\
\hline $\begin{array}{l}\text { I would be interested in a similar practice-based } \\
\text { MOOC on electronics but more advanced than this } \\
\text { MOOC }\end{array}$ & 70 & $27,70 \%$ \\
\hline $\begin{array}{l}\text { I would be interested in a theoretical MOOC on } \\
\text { electronics (without practical experiences and the } \\
\text { remote lab VISIR) }\end{array}$ & 28 & $11,10 \%$ \\
\hline I'm not interested in new MOOCs & 3 & $1,20 \%$ \\
\hline I'm not interested in a re-edition of this MOOC & 4 & $1,60 \%$ \\
\hline
\end{tabular}

In fact, only $33.84 \%$ of those enrolled have some training related to electrical/electronics engineering previously to the MOOC; $20.27 \%$ had some type of training related to engineering but not with the electrical/electronics area. Therefore, only $33.84 \%$ of those enrolled had the training required as is specified in the syllabus of the MOOC. This lack of academic training in electrical/electronics area has been reflected both in first modules dropout (Figure 1), especially in first modules which have supposed a significant filter, and in pre-course non-evaluative exam/test. As a negative data, only $11.73 \%$ of enrollments were women but this percentage increases over $17 \%$ for younger students.

The age of students is distributed evenly. Slightly stands out the group of students over 40 years old. By contrast, the group of students under 20 years old was the minority one.

$14^{\text {th }}$ LACCEI International Multi-Conference for Engineering, Education, and Technology: “Engineering Innovations for Global Sustainability”, 20-22 July 2016, San José, Costa Rica. 
This results are shown in Figure 3. Regarding to students' availability of time, Figure 3 also shows the labor status of students.

\section{E. Design of a New Structure in Moodle}

The high dropout and its analysis suggest that students need a theoretical framework to jump successfully into experimentation as well as learning scaffolding designed for novice electronics students. According to students' opinion (Figure 2 and Figure 4), the activities in BCEP MOOC should be simplified. It is going to be carried out by simplifying the number of concepts to analyze in each practical session and increasing the number of practical sessions. In addition, the labor situation of enrolled students (Figure 3) do not allow them to waste time, an affordable solution is to offer them lighter and more fluid courses (this does not mean easier courses, but courses with a smoother learning curve), stimulating them to advance. Accordingly, BCEP MOOC is going to be distributed in a family small MOOCs (adding experiences for novice students and expertise ones), complementing and adding certain experiments and including videos, tools and documents for circuit analysis.

Recycled experiments from BCEP MOOC and new designed experiments (which are not implemented yet) are not just to show waveforms of typical circuit operation with real components, they also must emphasize common mistakes, highlight students the gap between ideal modelling and real behavior. Furthermore, the disadvantages and limitations of working with real components and instruments have to be shown through activities designed for this purpose.

Given the students' profile enrolled in the course (previously to the course only 33.84\% had some type of training in electrical/electronics area), this kind of courses, with a design according to the learning objectives, can be used by educational institutions as a claim for potential enrollments in the field of engineering. In this respect, the interest in electrical/electronics field from potential students under 20 years old (group with minority of enrollments in BCEP MOOC and with the greatest potential interest from universities) should be achieved by means of the design of MOOCs based on experimentation but containing at least a basic theoretical framework, with which novice students could be able to understand the behavior of the components and circuits used in the remote experimentation, so they are introduced to a unconnected knowledge area for them until then. Getting access to school-age students through educational institutions and covering their teachers' concerns by means of designing/adapting MOOCs for this group of students could benefit students, teachers, educational institutions and universities providing a more complete education and bringing university to potential students.

The structure of this family of MOOCs can be seen as a stairs where every MOOC is a step in which each student may begin (according to their prior knowledge and training) and go up to higher levels, avoiding to attend unnecessary contents or training.

\section{BOOKING SYSTEM}

The limitation imposed by VISIR on the number of simultaneous users that it is able to manage in a satisfactory way requires the use of a booking system. VISIR has its own reservation system, however it requires user authentication. To prevent users from having to administer two user accounts, one for UNED-COMA platform and grant the access to the course and another one for VISIR remote lab, it was necessary to create the resource "booking system" in UNED-COMA platform.

\section{F. Booking System in UNED-COMA}

UNED-COMA sends data coded in a json file: authentication token and id-slot; the resource decode the json and sends back a request to check that the the data received by means of an Application Programming Interface key (API key). This resource is not designed exclusively for VISIR access, but is designed for any kind of tool which requires a previous reservation; for example, video-conferencing or web conferencing through AVIP classrooms (Audiovisual tool over IP technology) developed by UNED-INTECCA (Technological Innovation and Development in the Study Centers) [19].

The settings used in the booking system from UNEDCOMA for the three BCEP editions has been: 16 concurrent users per turn, 60 minutes per turn, a maximum of 2 simultaneous turns reserved per user and a limitation of 14 reserves throughout the course. With these settings, VISIR allows a maximum of 384 students to experiment with any of the practices designed in MOOC daily. This configuration may have been altered during MOOC depending on the demand, but it was not necessary.

The booking system was developed from the side of the MOOC platform, but it was also required to develop a new authentication service in VISIR for users from UNED-COMA platform. The new (mooc-user access) and existing (traditional access) authentication systems "live" together: both authentication services coexist. Students from other courses, teachers and administrators have accessed VISIR following the traditional process, meanwhile UNED-COMA users have interacted with the new authentication services. Both authentication services are showed in Figure 6.

However, this design in order to simplify access to students from MOOC BCEP has not been the most suitable for a post-analysis of students' behavior: the interaction between MOOC BCEP hosted in UNED-COMA platform and remote laboratory VISIR is not carried out as a whole but as two separate entities. The communication between the UNEDCOMA platform and remote laboratory has a gap because it is focused on the veracity of the access request and ignores user

$14^{\text {th }}$ LACCEI International Multi-Conference for Engineering, Education, and Technology: “Engineering Innovations for Global Sustainability”, 20-22 July 2016, San José, Costa Rica. 


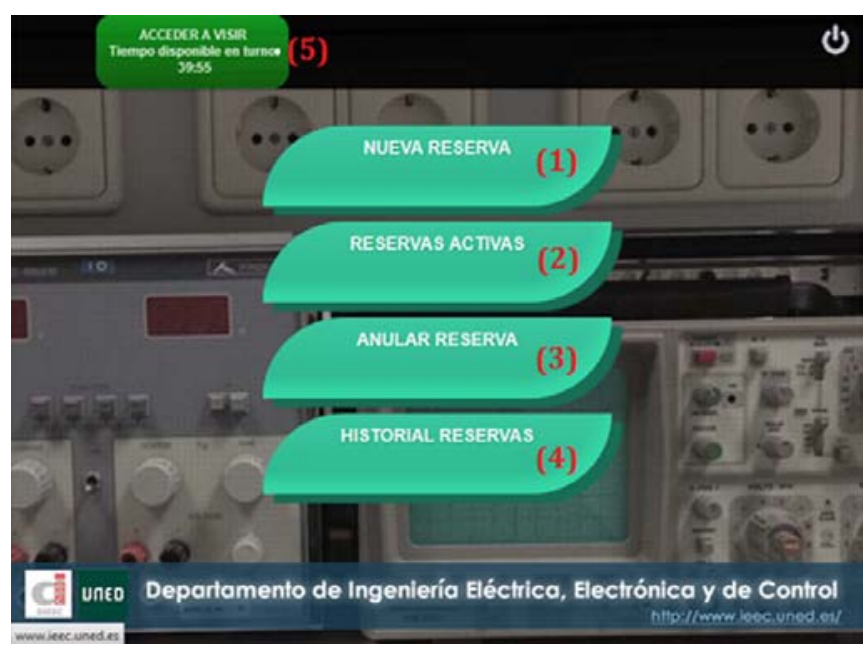

Figure 5: External booking system.

information, so, in the eyes of VISIR, all the users with a reservation from UNED-COMA are correctly authenticated in VISIR but anonymously.

Moreover, certain special experiments designed for advanced courses require full access to the lab (cannot share the resources of the remote lab). When these advanced courses need the access to VISIR, it entails to avoid access from UNED-COMA platform and to limit the number of users in the laboratory simultaneously to 1 (because of these special experiments which require full access). No booking system (UNED-COMA or VISIR) envisage the possibility that certain practices require full access to the laboratory, so only the max of simultaneous users can be configured and this setting is used for the entire laboratory (courses, experiments, etc.).

\section{G. New Booking System External to LMSs}

To prevent and correct all the problems and peculiarities of the different courses, an external booking system for VISIR has been developed (Figure 5). This new booking system allows to teacher/administrator to configure the number of slots per turn, the number of slots that an experiment needs (in order to set full access to those special experiments previously commented), the max of reservations for a course/practice or to set the max of active reservations (future turns) that a user can have. All this settings can be different for all the LMS that use VISIR at UNED and can coexists together. Moreover, this new booking system can be used for other purposes and for other remote laboratories performing small changes (establishing limits, labeling new experiments, etc.).

Students can make a new reservation (1), check the status of their active reservations (2) (remaining time to be activated), cancel a reservation (3) (at least 2 hours before activating) or consult their reservations history (4). They also have a direct access to the lab (5) "access to VISIR" in case there are available seats in the turn using a reservation ticket for the course the student access from (a pop-up message advice the student). In case the student have a reservation in the turn, the direct access (5) turn into "access to VISIR reservation".

Nowadays, this booking system is only available in Spanish. Once it has been tested in the Moodle platform with new MOOC courses, a version 2.0, which is going to include other languages, will be developed so it could be used by the VISIR community [20]-[10].

\section{H. Booking System Structure}

The external booking system is written in php and javascript and database is built in MySQL. It is completely web-responsive to facilitate its use on mobile platforms like smartphones or tablets (see Figure 9). In the database is stored, besides the required data (user' $s$ identifier, course identifier, experiment identifier, reservation status <active $\leftrightarrow$ cancelled $>$ and reservation datetime), some information in order to analyze the interaction of users/students with the booking system (moment the reservation is generated, if the

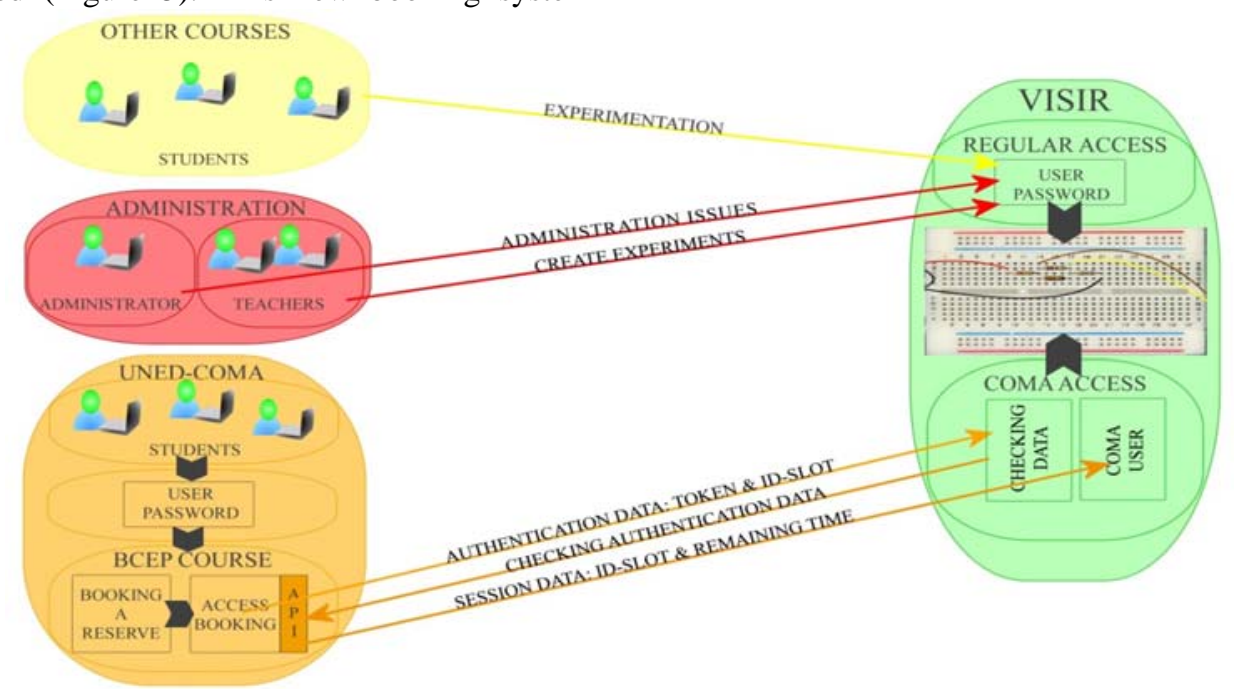

Figure 6: Authentication services in VISIR.

$14^{\text {th }}$ LACCEI International Multi-Conference for Engineering, Education, and Technology: "Engineering Innovations for Global Sustainability”, 20-22 July 2016, San José, Costa Rica. 


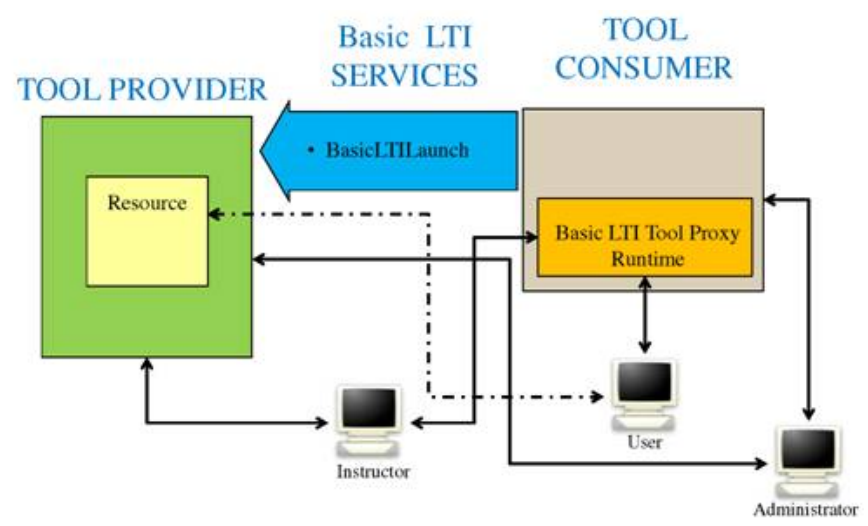

Figure 7: Overview of Basic LTI.

Source: IMS Global Learning Consortium [27].

user/student have use the reservation and the moment that the reservation is used, datetime in case of canceled reservations, etc.). The user's email is stored too. Users receive a confirmation email when they achieve a reservation or when they cancel a previous reservation. Booking system also will send reminders, previous the activation of a reservation, to users.

The communication between Moodle platform and the external booking system is carried out through Moodle External Tool. The External Tool enables Moodle users to interact with LTI-compliant learning resources and activities on other web sites [24], [25]. Students only need to log into Moodle and access to the booking system already identified; they do not have to log in a second time. Once the student access the booking system from Moodle LMS, the information is stored in a php session. LTI services prevents both identity spoofing during the launch phase and grade tampering during the grade passback phase [28]. Learning Tools Interoperability ${ }^{\circledR}\left(\mathrm{LTI}^{\circledR}\right)$ is a specification developed by IMS Global Learning Consortium. The principal concept of LTI is to establish a standard way of integrating rich learning

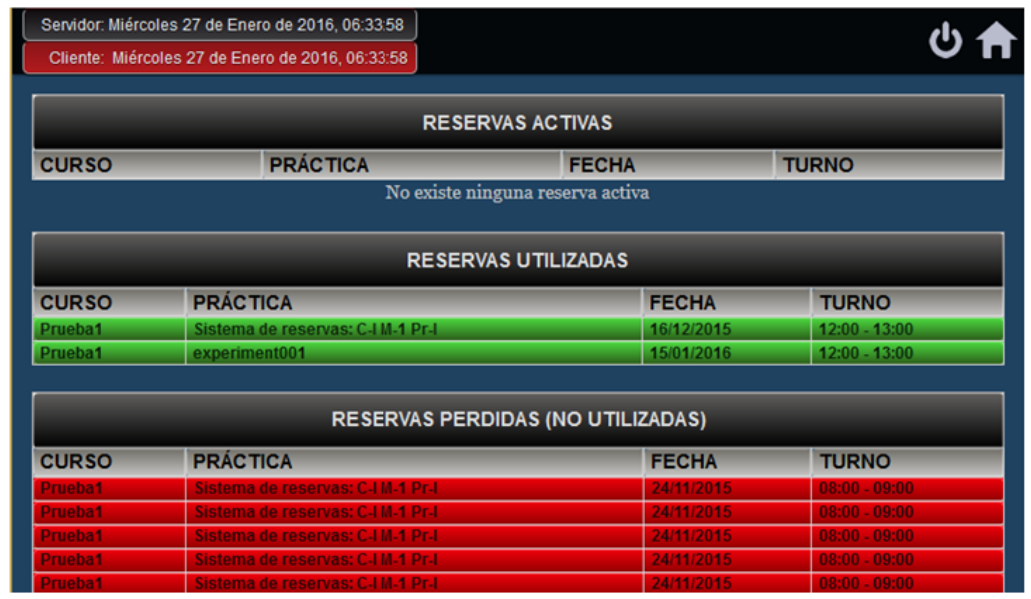
Moodle.

applications often remotely hosted and provided through third-party services (tool providers) with platforms like learning management systems, portals, learning object repositories, or other educational environments (tool consumers) [26], [27], [29], [30]. The LTI security model is based on OAuth, an open protocol to allow secure authorization in a simple and standard method from web, mobile and desktop application [28].

The basic use case behind the development of the LTI specification is to allow the seamless connection of webbased, externally hosted applications and content or Tools to platforms that present them to users [30].

For the interaction between LMS Moodle (tool consumer) and booking system (tool provider) it is enough by means of a basic LTI (as shown in Figure 8) due to there is not a grading tool in VISIR neither in booking system to feedback LMS

\section{Access to Remote Lab VISIR from Booking System}

The access to VISIR once a reservation is active or, if there are slots available (5 in Figure 5), using the direct access is granted by WebLab-Deusto installed in DIEEC-UNED

Figure 9: Web-responsive history on booking system. Screenshots of the same web-page with different resolutions.

$14^{\text {th }}$ LACCEI International Multi-Conference for Engineering, Education, and Technology: “Engineering Innovations for Global Sustainability”, 20-22 July 2016, San José, Costa Rica.

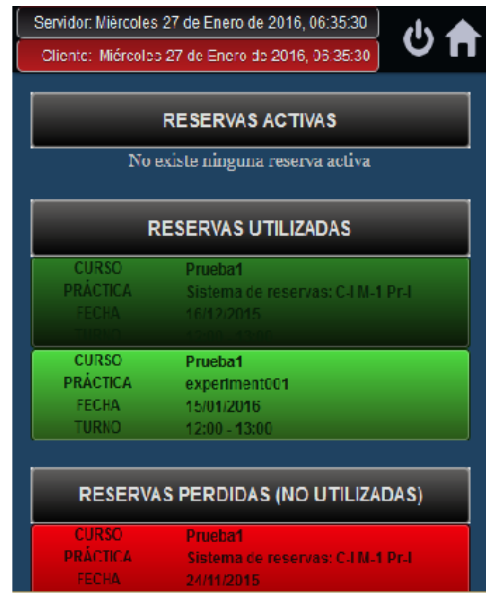


(Figure 8). WebLab-Deusto is an Open Source (BSD 2-clause license) remote laboratory management system developed in the University of Deusto [32].

WebLab-Deusto provides an extensible authentication mechanism (OAuth 2.0, OpenID, Based on IP (TrustedIP system), LDAP (Lightweight Directory Access Protocol) or based on plug-ins [31]. This way, all users are stored in the database, but different UserAuth mechanisms can be used for each user. The system will check for each user what mechanisms are available, and will check the credentials with each system. If any of the mechanisms say that the user is valid, the authentication mechanism will understand that it's a valid user [31], [33]. So, students only need to log into LMS Moodle and access to the booking system and VISIR without new logins and accessing the experiment in the simulated workbench of VISIR directly from the booking system, this means that users do not have to interact with WebLab-Deusto or VISIR administrative tools (logins, courses, access to the lab, etc.), they are hidden for users.

Additionally, WebLab-Deusto incorporates several useful tools for analyzing the experimentation and use within remote lab by students (Figure 10). It can even reproduce all the activities carried out by students in the remote laboratory, this is a powerful tool for SPOCs (Small Private Online Course). Moreover, when the user gets his circuit ready and clicks on the perform experiment button, the client PC (experiment client) starts to call the "measurement server" through experiment protocol, which is an XML based protocol; WebLab-Deusto stores all traffic (XML requests) between the experiment client and the measurement server. If the request is correct, the measurement server manage the queue of requests and sends the XML to the equipment server to wire physically the circuit in the component matrix. This stored data or requests allows to analyze in depth both individually and globally the behavior of users or designed experiments.

\section{CONCLUSIONS AND FUTURE WORK}

The framework and structure of the overall system is defined, and the development of most blocks are evolving in parallel. There is already fully operational subsystems, such as the access from Moodle to VISIR, through the booking system and WebLab-Deusto; other blocks are in an advanced stage, such as the migration to HTML5 or the contents of the family MOOCs. It remains to establish each MOOC divisions within the family and their limits coherently (delimit "how big is going to be each step of the stairs").

However, the biggest challenge to be faced is the analysis of the data and information that will be gathered. The data that the three systems (Moodle, the booking system and WebLabDeusto) are going to collect may be overwhelming. The parameters and statistics, that have to help the different teaching staffs to evaluate instructional materials and tools provided to students, have to be delicately selected in order to achieve the desired results: the adequacy of experiments designed, the interaction between the student and the system, etc. It is also pretended to parameterize the dropout reasons and causes, to analyze the behavior of students as they acquire the knowledge, etc.

\section{ACKNOWLEDGMENT}

The authors acknowledge the support provided by the Engineering Industrial School of UNED (Special Project on Remote Laboratories equipment 2014-2015-2016). And the partial support of the eMadrid project (Investigación y desarrollo de tecnologías educativas en la Comunidad de Madrid) - S2013/ICE-2715, VISIR+ project (Educational

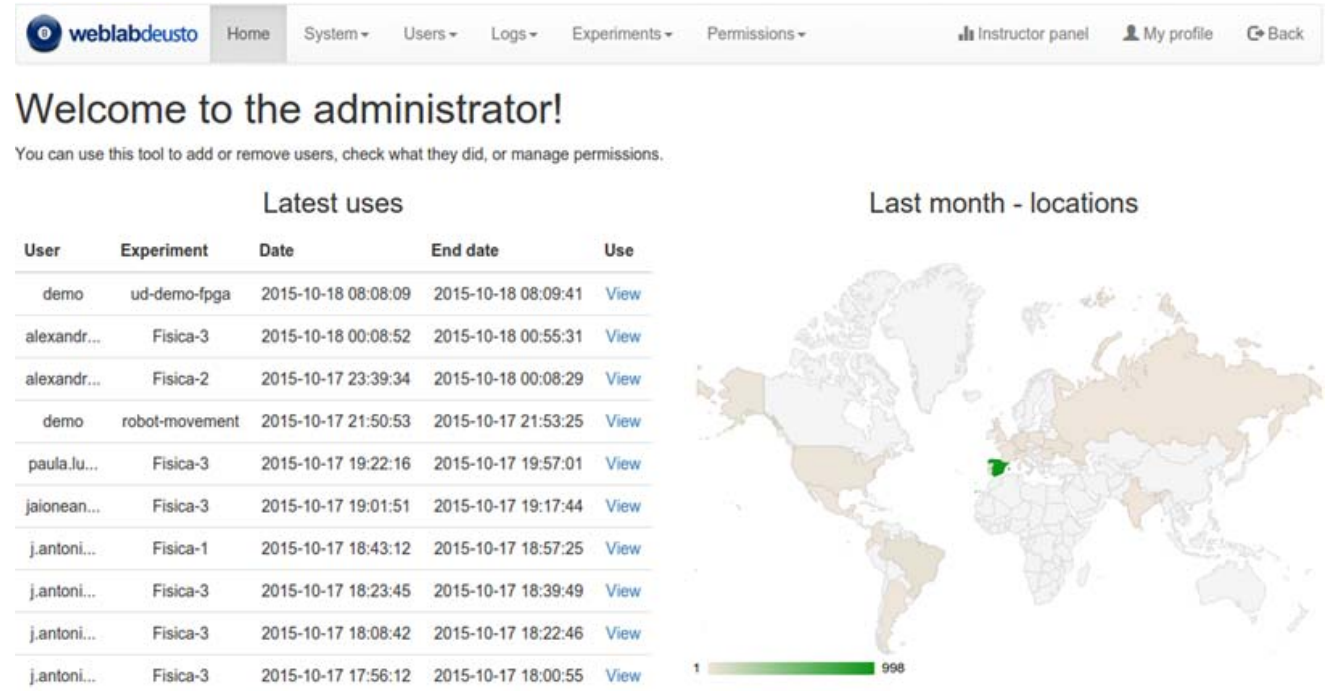

Figure 10: WebLab-Deusto: Users’ activity. Source: WebLab-Deusto [33].

$14^{\text {th }}$ LACCEI International Multi-Conference for Engineering, Education, and Technology: “Engineering Innovations for Global Sustainability”, 20-22 July 2016, San José, Costa Rica. 
Modules for Electric and Electronic Circuits Theory and Practice following an Enquiry-based Teaching and Learning Methodology supported by VISIR) Erasmus+ Capacity Building in Higher Education 2015 n ${ }^{\circ}$ 561735-EPP-1-2015-1PT-EPPKA2-CBHE-JP and Go-Labproject "Global Online Science Labs for Inquiry Learning at School” (FP7-ICT-20118 - Project number 317601).

\section{REFERENCES}

[1] Tawfik, M., Sancristobal, E., Martin, S., Gil, R.., Diaz, G., Colmenar, A., Peire, J., Castro, M., Nilsson, K., Zackrisson, J., Håkansson, L., Gustavsson, I., "Virtual Instrument Systems in Reality (VISIR) for Remote Wiring and Measurement of Electronic Circuits on Breadboard”, IEEE Transactions on Industrial Electronics,, vol. 6, no. 1, pp. 60-72. March, 2013.

[2] Naef, O., (2006). "Real Laboratory, virtual laboratory or remote laboratory: what is the most effective way?”. Intl. Journal of Online Engineering, Vol 2, No.3.

[3] Hanson, B., Culmer, P., Gallagher, J., Page, K., Read, E., Weightman, A., Levesley, M. "ReLOAD: Real Laboratories Operated at a Distance”. IEEE Transactions on Vol. 2, Issue: 4., pp. 331-341. 2009

[4] Nedic, Z., Machotka, J., Nafalski, A., "Remote laboratories versus virtual and real laboratories", 34th ASEE/IEEE frontiers in education conference, session T3E-1, pp.1-6. November 2003.

[5] Coble, A., Smallbone, A., Bhave, A., Watson, R., Braumann, A., Kraft, M. "Delivering authentic experiences for engineering students and professionals through e-labs”. IEEE EDUCON. pp 1085 - 1090. 2010.

[6] Sancristobal, E., Martin, S., Gil, R., Orduna, P., Tawfik, M., Pesquera, A., Diaz, G., Colmenar, A., Garcia-Zubia, J., Castro, M., "State of Art, Initiatives and New Challenges for Virtual and Remote Labs". IEEE 12th International Conference on Advanced Learning Technologies, ICALT. pp.714-715, Jul 2012.

[7] Potkonjak, V., Vukobratovic, M., Jovanovic, K., Medenica, M.."Virtual Mechatronic/Robotic laboratory - A step further in distance learning”. Computers \& Education. Vol 55 pp 465-475, 2010.

[8] Jara, C.A., Candelas, F.A., Puente, S.T., Torres, F., "Hands-on experiences of undergraduate students in Automatics and Robotics using a virtual and remote laboratory". Computers \& Education. Vol 57 pp 2451-2461, 2011.

[9] Rojko, A., Hercog, D., Jezernik, K., "Power Engineering and Motion Control Web Laboratory: Design, Implementation, and Evaluation of Mechatronics Course” IEEE Transactions on Industrial Electronics, Vol. 57, No. 10, pp. 3343- 3354, October 2010.

[10] Vivar, M.A, Magna, A.R., "Design, implementation and use of a remote network lab as an aid to support teaching computer network”. Third International Conference on Digital Information Management, ICDIM, London (UK), 13-16 Nov. 2008.

[11] Gustavsson, I., Nilsson, K., Lagö, T.L., "The VISIR Open Lab Platform". Chapter in book "Internet Accessible Remote Laboratories: Scalable E-Learning Tools for Engineering and Science Disciplines", by Abul K.M. Azad, Michael E. Auer, and V. Judson Harward (Editors). Engineering Science Reference, 2012. ISBN 978-1-61350186-3. pp. 294-317.

[12] Sheridan, T.B., "Descartes, Heidegger, Gibson, and God: Towards an Eclectic Ontology of Presence,” Presence: Teleoperators and Virtual Environments, vol. 8, no. 5, pp. 551-559, 1999.

[13] Biocca, F., "Inserting the Presence of Mind into a Philosophy of Presence: A Response to Sheridan and Mantovaniand Riva,” Presence. vol. 10, no. 5, pp. 546-556, 2001.
[14] Ma, J., Nickerson, J.V., "Hands-On, Simulated, and Remote Laboratories: A Comparative Literature Review”. ACM Computing Surveys, vol. 38, no. 3, 2006.

[15] Lang, D., Mengelkamp, C., Jager, R.S., Geoffroy, D., Billaud, M., Zimmer, T., "Pedagogical Evaluation of Remote Laboratories in eMerge Project”. European J. Eng. Education, vol. 32, no. 1, pp. 57- 72, 2007.

[16] Lindsay, E.D., Good, M.C., "Effects of Laboratory Access Modes Upon Learning Outcomes”. IEEE Trans. Education, vol. 48, no. 4, pp. 619-631, 2005

[17] Moodle. "Moodle - Open-source learning platform". [Online]. Available: http://www.moodle.org. [Accessed: 28- Jan- 2016].

[18] J. Swope, J."A Comparison of Five Free MOOC Platforms for Educators", EdTech. 2014, [Online]. Available: http://www.edtechmagazine.com/higher/article/2014/02/comparisonfive-free-mooc-platforms-educators. [Accessed: 28- Jan- 2016].

[19] Intecca.uned.es, "INTECCA | ¿Qué es AVIP?", 2016. [Online]. Available: https://www.intecca.uned.es/inteccainfo/plataformaavip/que-es-avip/. [Accessed: 25- Jan- 2016].

[20] VISIR SIG, Online-engineering.org. "VISIR Special Interest Groups (SIG)". [Online]. Available: http://www.onlineengineering.org/SIG_visir.php. [Accessed: 27- Jan- 2016].

[21] UNED-DIEEC. "VISIR - Electronics Remote Lab « Research on Technologies for Engineering Education", 2016. [Online]. Available: http://ohm.ieec.uned.es/portal/?page_id=76. [Accessed: 26- Jan- 2016].

[22] Openlabs. "OpenLabs - ElectroLab", 2016. [Online]. Available: http://openlabs.bth.se/index.php?page=ElectroLab. [Accessed: 26- Jan2016].

[23] UNED Abierta, "UNED Abierta", 2015. [Online]. Available: https://unedabierta.uned.es/wp/. [Accessed: 01- Dec- 2015].

[24] Moodle, moodle.org, "External Tool". [Online]. Available: https://docs.moodle.org/29/en/External_tool. [Accessed: 26- Jan2016].

[25] Moodle, moodle.org. "Using External tool - MoodleDocs". [Online]. Available:

https://docs.moodle.org/23/en/Using_External_tool\#Why_use_an_exter nal_tool.3F. [Accessed: 26- Jan- 2016].

[26] IMS Global Learning Consortium, Imsglobal.org, " IMS Global $\begin{array}{lll}\text { Learning } \quad \text { Consortium". } & \text { [Online]. } & \text { Available: }\end{array}$ https://www.imsglobal.org/. [Accessed: 26- Jan- 2016].

[27] IMS Global Learning Consortium, Imsglobal.org."IMS Global Learning Tools Interoperability Basic LTI Implementation Guide”. [Online]. https://www.imsglobal.org/specs/ltiv1p0/implementation-guide. [Accessed: 26- Jan- 2016].

[28] Coursera Technology, Tech.coursera.org. "LTI Integration". [Online]. Available: https://tech.coursera.org/app-platform/lti/. [Accessed: 26Jan- 2016].

[29] Oauth.net. "OAuth Community Site". [Online]. Available: http://oauth.net/. [Accessed: 26- Jan- 2016].

[30] IMS Global Learning Consortium, Imsglobal.org, "Learning Tools Interoperability® Background". [Online]. Available: https://www.imsglobal.org/activity/learning-tools-interoperability. [Accessed: 26- Jan- 2016].

[31] WebLab-Deusto, documentation."Authentication". [Online]. Available: https://weblabdeusto.readthedocs.org/en/latest/authentication.html. [Accessed: 26- Jan- 2016].

[32] Weblab-Deusto. [Online]. Available: http://weblab.deusto.es/website/. [Accessed: 26- Jan- 2016].

[33] Weblab Deusto, Weblabdeusto.readthedocs.org. " WebLab-Deusto 5.0 documentation",. $\quad$ [Online]. Available: https://weblabdeusto.readthedocs.org/en/latest/screenshots.html. [Accessed: 26- Jan- 2016]. 